\title{
LOGO DAN SIGNAGE SEBAGAI IDENTITAS VISUAL (STUDI KASUS: STADION GELORA BANDUNG LAUTAN API)
}

\author{
Federico Doriana Pratama1, Wirania Swasty² \\ 1,2 Desain Komunikasi Visual, Fakultas Industri Kreatif, Universitas Telkom \\ federicodoriana@gmail.com ${ }^{1}$, wirania@telkomuniversity.ac.id ${ }^{2}$
}

\begin{abstract}
Abstrak
Stadion Gelora Bandung Lautan Api sebagai kasus studi merupakan stadion terbesar di Kota Bandung yang dirancang berstandar internasional dan diklaim menjadi stadion termegah seIndonesia. Stadion yang mampu menampung 72.000 orang ini adalah salah satu potensi yang luar biasa bagi Bandung. Menjadi stadion terbesar di Jawa Barat, signage memiliki peranan penting agar memudahkan pengunjung untuk menuju ke lokasi yang akan dituju dengan cepat dan tepat. Beberapa area pada Stadion Bandung Lautan Api belum memiliki signage yang informatif, selain itu desain signage juga belum menunjukan konsistensi dan ciri khas dari stadion. Metode pengumpulan data yang digunakan yaitu observasi, wawancara, kuesioner dan studi pustaka. Adapun analisis data menggunakan matriks perbandingan. Hasil akhir berupa perancangan signage Stadion Gelora Bandung Lautan Api yang informatif dan menunjukkan identitas bangunan stadion maupun identitas Kota Bandung. Perancangan ini diharapkan dapat membantu pengunjung Stadion Gelora Bandung Lautan Api menemukan informasi atau arah sehingga mudah menuju tempat yang mereka inginkan dengan cepat dan tepat selama berada di dalam dan luar stadion.
\end{abstract}

Kata Kunci: identitas visual, signage, Stadion Gelora Bandung Lautan Api

\begin{abstract}
Gelora Bandung Lautan Api Stadium as a case study is the largest stadium in Bandung designed internationally and claimed to be the grandest stadium in Indonesia. The stadium that can accommodate 72,000 people is one of the tremendous potential for Bandung. Being the largest stadium in West Java, signage has an important role to facilitate visitors to get to the location to be addressed quickly and precisely. Some areas at Gelora Bandung Lautan Api Stadium have no informative signage, moreover the signage design has not shown the consistency and characteristic of the stadium. The data collection used are observation, interview, questionnaire and literature study. The data analysis used comparison matrix. The result of the design of signage Gelora Bandung Lautan Api Stadium that informative and show the identity of the building and Bandung identity. This design is expected to help visitors to find information or directions easyly to get to where they want quickly and precisely while inside and outside the stadium.
\end{abstract}

Keywords: visual identity, signage, Gelora Bandung Lautan Api Stadium 


\section{PENDAHULUAN}

Olahraga sebagai kegiatan yang paling diminati masyarakat Indonesia, selayaknya diadakan sarana pendukung untuk meningkatkan mutu olahraga salah satunya dengan dibangunnya stadion. Keberadaan stadion selain sebagai sarana olahraga dan hiburan bagi penonton, juga sebagai ruang terbuka untuk berkumpul. Stadion Gelora Bandung Lautan Api ini merupakan stadion terbesar di Kota Bandung. Dibangun di atas lahan 24,5 hektare stadion ini menjadi salah satu stadion paling megah di Indonesia yang dirancang sebagai stadion bertaraf internasional dan dapat menampung pengunjung sampai 72.000 orang jika tanpa kursi. Selain memiliki lapangan sepak bola, stadion ini juga dilengkapi dengan fasilitas penunjang lainnya seperti atletik, kantor, sirkulasi, $e$ board, scoring board, dan kursi tahan api yang merupakan standar FIFA.

Dengan banyaknya fasilitas yang ditawarkan Stadion Gelora Bandung Lautan Api, dibutuhkan sebuah signage mengenai informasi lokasi dan ruangan dari fasilitasfasilitas tersebut. Agar informasi dapat tersampaikan kepada pengunjung, signage diperlukan untuk mempermudah pengunjung mengetahui tata letak ruangan yang akan dituju dengan tepat. Selain itu dengan luas bangunan yang mencapai $72.000 \mathrm{~m}^{2}$ maka signage dapat menjadi solusi pengunjung untuk mengetahui lokasi yang dituju tanpa perlu menjelajahi stadion secara keseluruhan.

Berdasarkan pengamatan impiris, Stadion Gelora Bandung Lautan Api saat ini masih menggunakan signage yang belum terintregrasi dengan baik. Masih terdapat signage yang berukuran kecil sehingga keterbacaan kurang jelas, pemasangan signage juga belum menjangkau semua sisi ruangan baik di dalam dan luar ruangan, serta warna dan tipografi yang digunakan berbeda-beda sehingga signage sulit dikenali dan dipahami. Akibatnya banyak pengunjung yang kesulitan untuk mencari arah dan menemukan lokasi yang dituju. Signage yang baik merupakan tanda hasil komunikasi simbol dan teks pada daerah dengan mobilitas tinggi, tanpa tergantung bahasa verbal yang terbatas (Whitbeard, 2009). Dengan demikian, dengan adanya signage yang baik, informasi dari sebuah signage dapat membantu pengunjung stadion untuk mencari arah dan menemukan lokasi yang dituju dengan tepat.

Menurut Calori (2007: 5), signage dikenal sebagai petunjuk arah atau bisa juga sebagai petunjuk jalan, petunjuk lokasi, atau petunjuk informasi. Signage digunakan untuk mengarahkan atau mengiformasikan suatu tempat di lingkungan terbangun. Akan tetapi seiring berkembangnya zaman, signage menjadi kebutuhan yang luas dan tidak sekedar mengindentifikasikan area-area. Signage dan wayfinding adalah alat bantu sebagai penunjuk arah ke suatu lokasi yang dituju di lingkungan lokasi tersebut. Signage dibagi dalam beberapa jenis, antara lain Identification Sign, Directional Sign, Regulatory Sign, Interpretative Sign, Warning Sign dan Operational Sign. Gibson (2009:13) mengemukakan bahwa sign system harus merangkai suatu tempat baik komersil, publik, maupun pribadi, supaya dapat ditelusuri dengan teratur pada saat keramaian sekalipun. Signage yang baik menyajikan tanda eksplisit, informasi, beserta simbol yang jelas yang keseluruhannya mampu berkomunikasi secara cepat dan efektif. Dari teori yang telah dijabarkan di atas, disimpulkan bahwa signage adalah alat komunikasi 
untuk membantu setiap orang sebagai penunjuk arah untuk menemukan lokasi yang dituju.

Untuk membedakan Stadion Gelora Bandung Lautan Api (GBLA) dengan stadion lainnya, perlu adanya sebuah identitas visual. Identitas visual ini berfungsi sebagai informasi kepada masyarakat mengenai ciri khas Stadion Gelora Bandung Lautan Api. Selain itu identitas visual juga digunakan sebagai dasar perancangan signage agar ciri khas Stadion Gelora Bandung Lautan Api lebih terlihat oleh pengunjung. Menurut Rustan (2009:13), identitas visual adalah identitas yang berkaitan dengan citra atau image yang dipertahankan oleh perusahaan sebagai jembatan untuk menyatukan berbagai konteks dan audien bagi perusahaan tersebut. Fungsi dari identitas visual sendiri adalah untuk membedakan ciri sebuah perusahaan yang satu dengan perusahaan yang lainnya, sehingga masyarakat mengetahui identitas perusahaan tersebut dengan menggunakan elemen-elemen visual yang dipakai. Identitas visual salah satunya berupa logo yang sebaiknya didapat maknanya melalui pendekatan budaya perusahaan, historis atau aspirasi perusahaan yang kemudian disimbolkan (Soelarko, 1980 dalam Putera \& Swasty, 2017).

Dari fenomena yang telah dijabarkan di atas, rumusan permasalahan yang didapat adalah: 1) Stadion Gelora Bandung Lautan Api belum memiliki identitas visual yang membedakannya dengan stadion yang lainnya. 2) Signage yang ada saat ini kurang menampilkan informasi tentang fasilitas-fasilitas dan memiliki ukuran kecil sehingga sulit dibaca pada jarak tertentu.

\section{METODE PENELITIAN}

Penelitian ini menggunakan Stadion Gelora Bandung Lautan Api sebagai kasus studi utama, dilakukan pada bulan Januari hingga Juli 2017. Metode penelitian ini menggunakan pendekatan kualitiatif dan kuantitatif. Metode pengumpulan data yang digunakan yaitu observasi yang mana dilakukan pengamatan secara langsung (Riduwan, 2004: 104) ke Stadion Gelora Bandung Lautan Api untuk memperoleh datadata untuk perancangan.

Wawancara dilakukan dengan pengelola GBLA dan arsitek atau desainer yang merancang signage sebelumnya, serta masyarakat yang sering berkunjung ke stadion. Adapun kuesioner ditujukan kepada masyarakat yang pernah berkunjung ke stadion. Studi pustaka digunakan sebagai sumber data yang dapat mendasari dalam proses perancangan signage. Dalam hal ini studi pustaka dilakukan dengan mengumpulkan informasi sebanyak-banyaknya dari kepustakaan yang berhubungan dengan signage yang bersumber dari buku, jurnal, report/laporan, dan berita. Setelah data terkumpul, kemudian dilakukan analisis data dengan membuat matriks perbandingan audit desain proyek sejenis. Adapun yang dibandingkan adalah signage eksisting Stadion GBLA dengan Stadion Pakansari Bogor dan National Stadium Singapura. 


\section{HASIL DAN PEMBAHASAN}

Stadion Gelora Bandung Lautan Api (GBLA) merupakan stadion bertaraf internasional di Indonesia, bersanding dengan Stadion Gelora Bung Karno (Jakarta), Stadion Jakabaring (Palembang) yang juga bertaraf Internasional. Selain memiliki lapangan sepakbola, dilengkapi juga dengan lapangan atletik, kantor, tribun atap full keliling, $e$ board, dan kursinya tahan api. Stadion ini mampu menampung $38.000-72.000$ penonton jika tanpa kursi. Jumlah Mushola dan toiletnya mencapai 766 buah dan terdapat ruang VVIP untuk kelas Kepala Negara (Presiden).

Dalam wawancara dengan Bapak Opik selaku pengelola Stadion Gelora Bandung Lautan Api, Opik (2017) menjelaskan bahwa signage memiliki peran yang sangat penting di dalam stadion, karena dengan adanya signage pengunjung akan dengan mudah menemukan tempat atau mencari informasi secara tepat. Beliau juga mengatakan bahwa signage yang ada di Stadion Gelora Bandung Lautan Api sudah sesuai dengan standar internasional dan sudah melewati beberapa pertimbangan. Selain itu untuk lebih mempermudah lagi, di setiap pintu masuk menuju stadion sudah diberikan papan peta untuk mengetahui lokasi dimana anda sekarang, dan lokasi-lokasi apa yang akan anda cari.

Wawancara tentang signage yang dilakukan dengan Endra Waskito selaku in house designer di Gusto Sign. Waskito (2017) berpendapat bahwa prinsip dalam membuat signage ialah mudah dibaca dan dilihat karena itu informasi secara visual yang akan disampaikan kepada masyarakat, dan signage harus mempertimbangkan beberapa elemen untuk penempatan seperti apakah signage itu akan ditempatkan di dalam ruangan atau di luar ruangan. Waskito (2017) juga menjelaskan bahwa identitas visual juga penting diterapkan pada signage, karena identitas visual dapat membantu untuk membuat konsep perancangan signage, unsur itu bisa seperti warna, bentuk, atau ornament. Dengan unsur-unsur tersebut nantinya akan menampilkan ciri khas yang ada di stadion tersebut

Wawancara juga dilakukan dengan Andi Rahmat selaku pemilik Nusae Studio. Rahmat (2017) menjelaskan bahwa dalam menentukan identitas visual, sebelumnya kira harus mengetahui tekniknya terlebih dahulu, karena khalayak sasaran dari desain adalah masyarakat. Rahmat (2017) juga berpendapat bahwa identitas visual untuk stadion bisa diambil dari lingkungan stadion tersebut. Identitas visual juga dirasa penting karena setiap stadion memiliki ciri khas yang berbeda.

Dari hasil wawancara dapat disimpulkan bahwa prinsip dalam membuat signage ialah mudah dibaca dan dilihat, selain itu identitas visual diperlukan karena setiap stadion memiliki ciri khas yang berbeda, dan identitas visual stadion bisa diambil dari lingkungan sekitar stadion tersebut. Stadion Gelora Bandung Lautan Api memerlukan signage di setiap pintu masuk menuju stadion untuk mempermudah pengunjung mengetahui keberadannya dan lokasi apa yang akan dituju. 
Berdasarkan hasil kuesioner yang disebar kepada pengunjung stadion berusia 15-30 tahun, didapatkan kesimpulan bahwa signage di dalam stadion kurang berfungsi dengan baik karena ukurannya yang terlalu kecil atau keterbacaannya kurang jelas. Hal ini membuat pengunjung perlu membaca lebih dekat. Responden menyukai signage yang menggunakan desain sederhana namun tetap menarik dan mudah dipahami.

Setelah data terkumpul, audit desain dilakukan dengan mendokumentasikan setiap jenis signage yang terdapat di Stadion Gelora Bandung Lautan Api kemudian dibandingkan dengan Stadion Pakansari Bogor dan National Stadium Singapura. Tabel 1 menunjukkan analisis signage pada ketiga stadion yang diobservasi.

Tabel 1. Analisis Matriks Perbandingan

[Sumber: Pratama \& Swasty, 2017]

\begin{tabular}{|c|c|c|c|}
\hline & $\begin{array}{l}\text { Stadion GBLA } \\
\text { Bandung }\end{array}$ & $\begin{array}{c}\text { Stadion Pakansari } \\
\text { Bogor }\end{array}$ & $\begin{array}{l}\text { National Stadium } \\
\text { Singapura }\end{array}$ \\
\hline Typografi & $\begin{array}{l}\text { Jenis huruf yang } \\
\text { digunakan pada } \\
\text { signage di Stadion } \\
\text { GBLA adalah jenis } \\
\text { sans serif }\end{array}$ & $\begin{array}{l}\text { Jenis huruf yang } \\
\text { digunakan pada } \\
\text { signage di Stadion } \\
\text { Pakansari adalah } \\
\text { jenis sans serif }\end{array}$ & $\begin{array}{l}\text { Jenis huruf yang } \\
\text { digunakan pada } \\
\text { signage di National } \\
\text { Stadium adalah jenis } \\
\text { sans serif }\end{array}$ \\
\hline Warna & $\begin{array}{l}\text { Warna yang } \\
\text { digunakan untuk } \\
\text { warna signage } \\
\text { adalah warna abu- } \\
\text { abu, dengan font } \\
\text { berwarna hitam. } \\
\text { Dengan memilih } \\
\text { warna tersebut akan } \\
\text { memberikan kesan } \\
\text { tenang }\end{array}$ & $\begin{array}{l}\text { Warna yang } \\
\text { digunakan untuk } \\
\text { warna signage } \\
\text { adalah warna } \\
\text { oranye, dengan font } \\
\text { berwarna hitam. } \\
\text { Dengan memilih } \\
\text { warna tersebut ini } \\
\text { menentukan bahwa } \\
\text { signage di stadion } \\
\text { ini menggunakan } \\
\text { warna yang eye } \\
\text { catching. }\end{array}$ & $\begin{array}{l}\text { Warna yang } \\
\text { digunakan untuk } \\
\text { signage adalah } \\
\text { warna merah } \\
\text { dengan font } \\
\text { berwarna putih. } \\
\text { Warna ini dipilih } \\
\text { karena simple dan } \\
\text { mudah untuk } \\
\text { dipahami oleh } \\
\text { masyarakat. }\end{array}$ \\
\hline Layout & $\begin{array}{l}\text { Simple, minimalis, } \\
\text { dan to the point }\end{array}$ & $\begin{array}{l}\text { Eye catching dan } \\
\text { simple }\end{array}$ & $\begin{array}{l}\text { Simple namun tidak } \\
\text { menghilangkan ciri } \\
\text { khasnya. }\end{array}$ \\
\hline
\end{tabular}




\begin{tabular}{|c|c|c|c|}
\hline Piktogram & $\begin{array}{l}\text { Piktogram yang } \\
\text { digunakan sudah } \\
\text { sesuai dengan } \\
\text { standard dan } \\
\text { keterbacaanya cukup } \\
\text { jelas }\end{array}$ & $\begin{array}{l}\text { Piktogram yang } \\
\text { digunakan sudah } \\
\text { sesuai dengan } \\
\text { standard dan } \\
\text { keterbacaanya } \\
\text { cukup jelas }\end{array}$ & $\begin{array}{l}\text { Piktogram yang } \\
\text { digunakan sudah } \\
\text { sesuai dengan } \\
\text { standard dan } \\
\text { keterbacaannya } \\
\text { cukup jelas }\end{array}$ \\
\hline Material & $\begin{array}{l}\text { Material yang } \\
\text { digunakan adalah } \\
\text { bahan fiber. }\end{array}$ & $\begin{array}{l}\text { Material yang } \\
\text { digunakan adalah } \\
\text { bahan fiber }\end{array}$ & $\begin{array}{l}\text { Material yang } \\
\text { digunakan ialah } \\
\text { berbahan akrilik. }\end{array}$ \\
\hline
\end{tabular}

Dari analisis data matriks, dapat diambil kesimpulan bahwa signage yang baik menggunakan huruf sans serif yang mudah dibaca dari jarak jauh. Selain itu penggunaan warna yang tepat adalah warna yang terang yang disesuaikan dengan identitas yang ingin ditampilkan dengan font hitam atau putih menyesuaikan warna signage. Piktogram dapat menggunakan piktogram standard namun tetap memiliki ciri khas dan keterbacaanya cukup jelas. Pemilihan bahan material juga disesuaikan dengan warna lingkungan.

Untuk menyampaikan tujuan komunikasi yang tepat pada sasaran pengunjung, pendekatan komunikasi verbal pada perancangan signage disajikan dengan menggunakan Bahasa Indonesia sebagai bahasa utama dan ditambahkan Bahasa Inggris agar dapat dipahami oleh wisatawan mancanegara. Acuan desain adalah dari logo Kota Bandung, dimana dari identitas visual tersebut dapat tercermin ciri khas Bandung agar penyampaian komunikasi dapat diterima dengan baik oleh pengunjung.

Perancangan signage dan identitas visual pada Stadion Gelora Bandung Lautan Api menggunakan tulisan dan gambar seperti hasil yang didapat dari data. Waskito (2017) berpendapat bahwa signage yang efektif terdiri dari gambar dan tulisan, oleh karena itu perancangan signage Stadion Gelora Bandung Lautan Api menggunakan kedua unsur tersebut. Konsep visual yang didapat dari mind mapping dijabarkan dalam Tabel 2 berikut.

Tabel 2. Konsep Visual

[Sumber: Pratama \& Swasty, 2017]

\begin{tabular}{cl}
\hline Kategori & \multicolumn{2}{c}{ Penjelasan } \\
\hline Tema & Tema yang diambil adalah ciri khas dari olahraga yaitu \\
& keberagaman dan dinamis yang bisa diartikan penuh semangat \\
& dan cepat dalam bergerak sehingga mudah menyesuaikan diri \\
& dengan keadaan. Selain itu tema lainnya adalah megah, yang \\
& diambil dari ciri stadion yang luas dan besar.
\end{tabular}




\begin{tabular}{cl}
\hline Warna & $\begin{array}{l}\text { Warna yang diambil dari warna ciri khas Bandung dan Dinas } \\
\text { Pemuda dan Olah Raga (DISPORA) yaitu warna biru sedangkan } \\
\text { logo menggunakan warna yang lebih beragam untuk memberikan } \\
\text { unsur keberagaman. }\end{array}$ \\
\hline Tipografi & $\begin{array}{l}\text { Tipografi yang digunakan adalah jenis sans serif yaiut font verdana } \\
\text { karena lebih mudah dibaca dari dekat maupun kejauhan, }\end{array}$ \\
\hline Bentuk & $\begin{array}{l}\text { Bentuk yang digunakan diambil dari logo Kota Bandung dan } \\
\text { bentuk dari stadion itu sendiri. }\end{array}$ \\
\hline
\end{tabular}

\subsection{KONSEP VISUAL DAN HASIL PERANCANGAN LOGO}

Bentuk dari desain logo menggambarkan konsep arsitektur bangunan Stadion Gelora Bandung Lautan Api. Bentuk yang akan diterapkan pada logo didapat dari bentuk bangunan stadion yang berbentuk oval dan elemen yang terdapat pada desain luar bangunan yaitu berupa corak-corak melengkung yang berulang-ulang. Warna diambil dari warna dari logo Kota Bandung yang mana terdapat warna hijau, biru, dan kuning. Penambahan warna juga diambil dari warna logo DISPORA (Dinas Pemuda dan Olahraga) yang berwarna biru, orange, merah dan hijau.

Dalam proses pembentukan identitas visual, dibutuhkan juga suatu bentuk logo. Logo adalah identitas yang dipergunakan untuk menggambarkan citra dan karakter suatu lembaga (Kusrianto, 2009). Logo digunakan sebagai identitas dari Gelora Bandung Lautan Api, yang nantinya akan ditempatkan pada media utama yaitu signage.

Desain Komunikasi Visual tidak dapat lepas dari tipografi sebagai unsur pendukungnya. Selain itu bentuk huruf yang dipilih dimana jenis huruf yang akan dipergunakan untuk judul dan judul diaplikasikan ke media utama yaitu signage. Untuk logo menggunakan satu font yang telah dimodifikasi. Tipografi yang dipakai untuk perancangan logo adalah Co-Headline. Jenis font ini yang terlihat tegas serta memiliki jarak yang tidak terlalu jauh dan tidak terlalu dekat antara huruf yang satu dengan huruf yang lain sehingga lebih mudah dibaca.

Logo Stadion Gelora Bandung Lautan Api ini (Gambar 1) merupakan penggabungan dari logotype dan logogram. Logogram merupakan visualisasi dari bentuk bangunan stadion yang dimodifikasi dan digabungkan dengan elemen bentuk yang terdapat dibagian luar Stadion Gelora Bandung Lautan Api, sedangkan logotype merupakan modifikasi dari font co-headline. Secara garis besar logo ini mempresentasikan keberagaman, semangat, antusiasme, dan serta sebuah keoptimisan. Logogram bisa dimodifikasi menggunakan satu warna yaitu warna biru sebagai warna dari media utama, serta hitam atau putih sebagai warna netral dan digunakan berdasarkan kebutuhan serta tidak merubah bentuk dasar logo itu sendiri. 


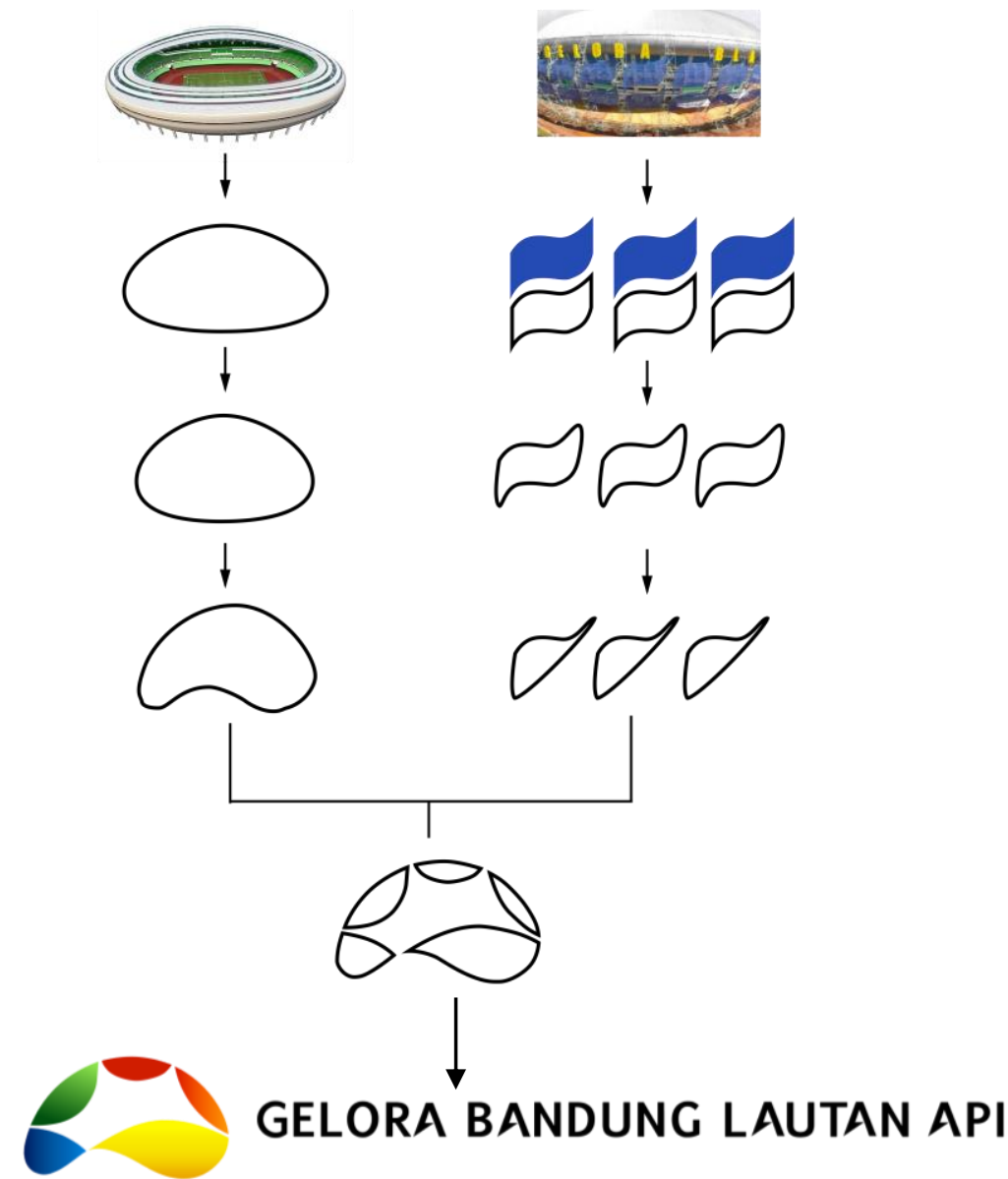

Gambar 1. Proses Perancangan Logo Gelora Bandung Lautan Api

[Sumber: Pratama \& Swasty, 2017]

\subsection{KONSEP VISUAL DAN HASIL PERANCANGAN SIGNAGE}

Ada dua jenis gambar yang akan ditampilkan pada signage yaitu piktogram (simbol dan tanda panah) serta motif logo Gelora Bandung Lautan Api. Bentuk yang akan diterapkan pada signage diperoleh dari tema konsep visual yang didapatkan dari moodboard dan mind maping yaitu memiliki bentuk yang dinamis sehingga dapat diartikan sebagai bentuk yang dapat disesuaikan dengan kondisi sekitar. Warna diambil dari warna logo Kota Bandung yang terdiri dari warna hijau, kuning, biru dan hitam yang kemudian dipilih warna biru sebagai warna utama dalam signage.

Warna yang digunakan pada tingkatan pesan, digunakan untuk menyampaikan pesan peraturan yang ada di dalam stadion dan pesan keadaan darurat, seperti signage wall mounted yang berisi pesan "dilarang merokok", "dilarang masuk", "dilarang membuang sampah sembarangan". Untuk warna penanda lokasi, signage yang digunakan berbentuk flag mounted dan wall mounted, sehingga setiap ruangan terdapat signage yang menggunakan warna tersebut. Kegunaan penanda lokasi adalah agar pengunjung dapat mengetahui ruangan yang ada di stadion, warna biru yang 
digunakan merupakan warna dasar signage yang diaplikasikan di seluruh penanda lokasi atau ruangan. Untuk warna biru, putih dan hitam pada gambar diatas, digunakan untuk warna yang utama signage. Alasan pemilihan warna biru, hitam dan putih, karena warna biru menampilkan kesan ciri khas dari Kota Bandung. Warna hitam mewakili warna yang netral dan mudah dilihat serta warna putih memberikan kesan bersih dan simpel. Signage yang berwarna biru yang dipadukan dengan warna hitam diletakkan di ruangan yang semi outdoor sehingga pengunjung lebih mudah melihat dari dekat atau pun dari kejauhan dengan warna biru tersebut. Untuk warna putih, seluruhnya diletakkan di dalam ruangan seperti signage jenis flag mounted dan wall mounted.

Tipografi yang dipakai pada perancangan signage ini adalah jenis Sans Serif karena tulisan lebih mudah dibaca dari dekat maupun kejauhan. Tipe Sans Serif ini juga menimbulkan kesan kesederhanaan yang tetap menampilkan kesan modern. Tipografi yang dipakai untuk perancangan signage adalah jenis font verdana. Jenis font verdana memiliki jarak yang tidak terlalu jauh dan tidak terlalu dekat antara huruf yang satu dengan huruf yang lain sehingga lebih mudah dibaca.

Berikut ini adalah hasil perancangan signage untuk Stadion Gelora Bandung Lautan Api. Perancangan Directional Sign dibagi menjadi empat jenis yaitu freestanding sign, suspended sign, wall mounted sign dan flag mounted sign. Untuk freestanding sign dibuat menggunakan bahan akrilik dan terdapat rangka di dalam, sehingga hasil akhir berupa signage dengan model neon box. Jenis suspended sign dibuat dengan bahan akrilik dan digantung dengan rantai besi. Flag mounted sign dibuat dengan alumunium dan ditempelkan dengan material tambahan yaitu besi untuk mengkaitkan signage ke dinding. Untuk wall mounted sign dibuat dengan bahan alumunium dan visual dari cutting sticker. Corak yang terdapat pada freestanding sign dan suspended sign dibuat dari logo Stadion Gelora Bandung Lautan Api sebagai identitas visual tetapi dengan warna biru agar tidak terlalu mendominasi dari signage itu sendiri. 
Suspended Sign

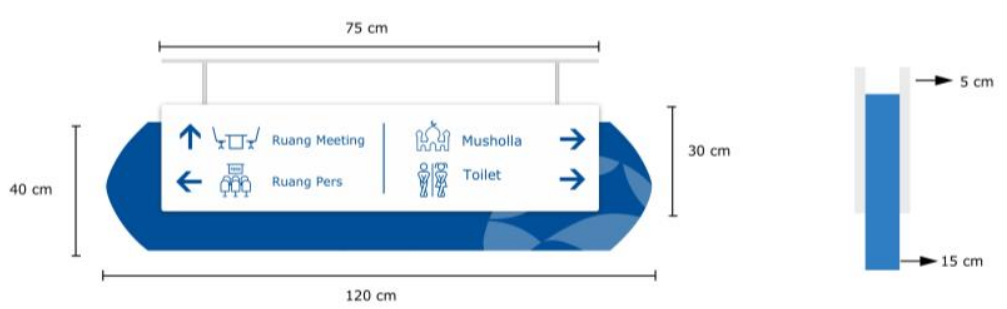

$120 \mathrm{~cm}$
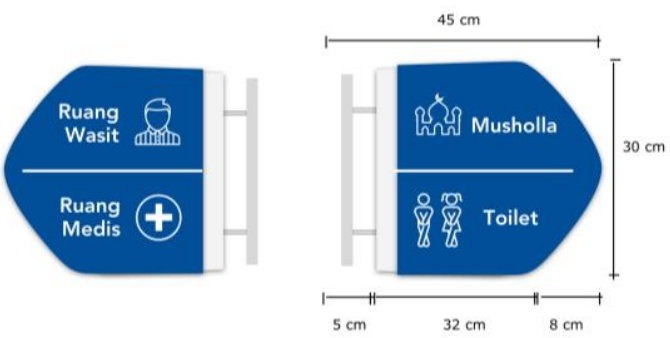

Freestanding Sign

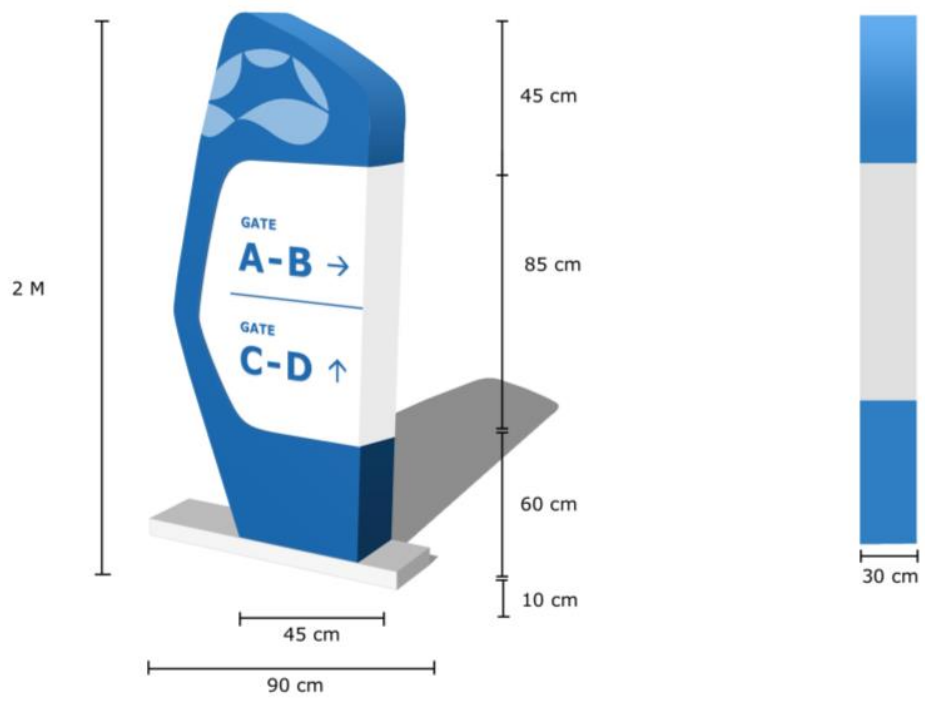

Gambar 2. Hasil Perancangan Signage

[Sumber: Pratama \& Swasty, 2017]

\section{KESIMPULAN}

Perancangan logo dan signage pada Stadion Gelora Bandung Lautan Api dirancang dengan mengadopsi unsur Kota Bandung dan olahraga sebagai penyampaian informasi petunjuk arah untuk membantu pengunjung dalam mengarahkan serta menemukan lokasi yang dituju. Melalui perancangan signage dan identitas visual ini diharapkan pengunjung di Stadion Gelora Bandung Lautan Api dapat dengan mudah mengenali ciri khas stadion serta mengetahui dimana lokasi mereka berada dan lokasi tujuan yang akan mereka tuju baik di dalam maupun luar stadion. 
Studi ini mengambil satu kasus studi utama yaitu Stadion Gelora Bandung Lautan Api dan terbatas pada studi logo, signage dan wayfinding sebagai identitas visual suatu ruang publik. Untuk penelitian selanjutnya, studi mengenai placemaking sebagai identitas visual yang diterapkan pada desain grafis untuk sebuah lingkungan terbangun termasuk seperti stadion, bandara, rumah sakit dan ruang publik lainnya menarik untuk diteliti.

\section{PERNYATAAN PENGHARGAAN}

Penulis mengucapkan terimakasih kepada Bapak Opik dari Stadion Gelora Bandung Lautan Api sebagai narasumber wawancara. Terimakasih juga kepada Bapak Andi Rahmat selaku designer dari Nusae Studio dan Bapak Endra Waskito selaku in house designer dari Gusto Sign sebagai narasumber wawancara dalam studi ini.

\section{DAFTAR PUSTAKA}

Calori, C., 2007. Signage and Wayfinding Design: A Complete Guide to Creating Environmental Graphic Design Systems. California: John Wiley \& Sons, Inc.

Gibson, D., 2009. The Wayfinding Handbook: Information Design for Public Places. New York: Princeton Architectural Press.

Kusrianto, A., 2009. Pengantar Desain Komunikasi Visual. s.I.:Andi.

Opik. 2017, 6 April. Wawancara pribadi

Putera, D. Y., \& Swasty, W. 2017. Perancangan Identitas Visual dan Pengaplikasian Pada Media Promosi Museum Sri Baduga. ANDHARUPA: Jurnal Desain Komunikasi Visual \& Multimedia, 3(02), 196-203.

Rahmat, A. 2017, 15 Maret. Wawancara pribadi

Riduwan, 2004. Metode dan Teknik Menyusun Tesis, Alfabeta: Bandung

Rustan, S., 2009. Mendesain Logo. Jakarta: PT. Gramedia Pustaka Utama.

Whitbeard, D., 2009. The Design Manual. s.I.:University of New South Wales Press.

Waskito, E. 2017. 10 Maret. Wawancara pribadi 